\title{
Incidence and risk factors of
}

\section{PostopeRativE delirium in intensive care}

\section{unit patients: A study protocol for the PREDICt study}

Cai, S

http://hdl.handle.net/10026.1/14654

10.1111/jan.14097

Journal of Advanced Nursing

Wiley

All content in PEARL is protected by copyright law. Author manuscripts are made available in accordance with publisher policies. Please cite only the published version using the details provided on the item record or document. In the absence of an open licence (e.g. Creative Commons), permissions for further reuse of content should be sought from the publisher or author. 
PROFESSOR YUXIA ZHANG (Orcid ID : 0000-0003-4419-7004)

Article type : Protocol

Incidence and risk factors of PostopeRativE Delirium in Intensive Care unit patients: a study

protocol for the PREDICt study

Running head: Incidence and risk factors of postoperative delirium in intensive care unit patients

\section{Authors}

Shining CAI MScN, RN ${ }^{1 \#}$; Minzhi LV, MD ${ }^{2 \#}$; Jos M. LATOUR, PhD, RN³ ; Ying LIN, RN ${ }^{4}$; Wenyan PAN, RN ${ }^{5}$; Jili ZHENG RN ${ }^{6}$; Lihong CHENG, $\mathrm{RN}^{7}$; Jingjing LI, RN ${ }^{8}$; Yuxia ZHANG, PhD, RN ${ }^{9}$

1. Department of Surgery Intensive Care Unit, Zhongshan Hospital, Fudan University, Shanghai, 200032, China. Email: cai.shining@zs-hospital.sh.cn

2. Department of Biostatistics, Zhongshan Hospital, Fudan University, Shanghai, 200032, China. Email:

This article has been accepted for publication and undergone full peer review (not applicable for Editorials) but has not been through the copyediting, typesetting, pagination and proofreading process, which may lead to differences between this version and the Version of Record. Please cite this article as doi: 10.1111/jan.14097

This article is protected by copyright. All rights reserved. 
lvminzhi@163.com

3. School of Nursing and Midwifery, Faculty of Health and Human Sciences, University of Plymouth, Plymouth, UK. Email: jos.latour@plymouth.ac.uk

4. Department of Nursing, Zhongshan Hospital, Fudan University, Shanghai, 200032, China Email: lin.ying@zs-hospital.sh.cn

5. Department of Surgery Intensive Care Unit, Zhongshan Hospital, Fudan University, Shanghai, 200032, China Email: pan.wenyan@zs-hospital.sh.cn

6. Department of Cardiac Surgery Intensive Care Unit, Zhongshan Hospital, Fudan University, Shanghai, 200032, China. Email: zheng.jili@zs-hospital.sh.cn

7. Department of Liver Surgery Intensive Care Unit, Zhongshan Hospital, Fudan University, Shanghai, 200032, China Email: cheng.lihong@zs-hospital.sh.cn

8. Department of Surgery Intensive Care Unit, Zhongshan Hospital, Fudan University, Shanghai, 200032, China Email: li.jingjing@zs-hospital.sh.cn

9. Department of Nursing, Zhongshan Hospital, Fudan University, Shanghai, 200032, China. Email: zhang.yuxia@zs-hospital.sh.cn

\# Equal contribution: Shining CAI and Minzhi LV should be considered joint first author.

\section{Corresponding author:}

Yuxia ZHANG, 180 Fenglin Road, Zhongshan Hospital, Fudan University, Shanghai, China, 200032

Tel: 86-21-64041990; Email: zhang.yuxia@zs-hospital.sh.cn

This article is protected by copyright. All rights reserved. 


\section{Author Contributions}

\begin{tabular}{|c|c|}
\hline Criteria & Author Initials \\
\hline $\begin{array}{l}\text { Made substantial contributions to conception and design, or acquisition of data, or } \\
\text { analysis and interpretation of data; }\end{array}$ & $\begin{array}{l}\text { Shining CAI, Mingzhi LV, } \\
\text { Yuxia ZHANG }\end{array}$ \\
\hline $\begin{array}{l}\text { Involved in drafting the manuscript or revising it critically for important intellectual } \\
\text { content; }\end{array}$ & Jos LATOUR, Yuxia ZHANG \\
\hline $\begin{array}{l}\text { Given final approval of the version to be published. Each author should have participated } \\
\text { sufficiently in the work to take public responsibility for appropriate portions of the } \\
\text { content; }\end{array}$ & Yuxia ZHANG, Jos LATOUR \\
\hline $\begin{array}{l}\text { Agreed to be accountable for all aspects of the work in ensuring that questions related to } \\
\text { the accuracy or integrity of any part of the work are appropriately investigated and } \\
\text { resolved. }\end{array}$ & $\begin{array}{l}\text { Ying LIN, Wenyan PAN, Jili } \\
\text { ZHENG, Lihong CHENG, } \\
\text { Jingjing LI }\end{array}$ \\
\hline
\end{tabular}

\section{Funding Statement:}

This study was funded by the Clinical Research Grant scheme of the Zhongshan Hospital, Fudan University in April 2018 (Grant No. 2018ZSLC08). The total amount of funding is 500,0000 RMB (equals to 72,257 US dollars).

\section{Conflict of Interest}

No conflict of interest has been declared by the authors.

This article is protected by copyright. All rights reserved. 


\section{Abstract}

Aim: The aims of this study are 1) to determine the incidence of postoperative delirium among surgical Intensive Care Unit patients in China and identify risk factors, especially which are modifiable and have value for developing a prediction model; 2) to develop and validate a prediction model of delirium to recognize high-risk patients in surgical Intensive Care Units; 3) to investigate the short- and long-term outcomes of delirious patients and identify the predictors of patient outcomes.

Design: A single centre prospective cohort study.

Methods: Patients will be enrolled from three surgical Intensive Care Units in a tertiary teaching hospital. Delirium assessment and perioperative data will be collected throughout the hospitalization.

Delirious patients will be followed up for 2 years. The study was approved by the ethics committee in

May 2018 and was funded by the clinical research grant from Zhongshan hospital, Fudan University,

Shanghai.

Discussion: Developing postoperative delirium can be a burden to patients both for the short- and

long-term period. Due to the lack of effective treatments for postoperative delirium, prevention remains the best strategy. This study will provide an effective tool for early screening of high-risk

This article is protected by copyright. All rights reserved. 
patients of postoperative delirium and provide a better understanding of the aetiology and outcome of

delirium.

Impact: In clinical practice, a prediction model will offer an effective tool for ICU nurses to assess

high-risk patients, which can support them to implement preventive strategies at the early stages to

targeted patients. The follow-up results will help us better understand the impact of delirium on

patients' long-term outcome.

Trial registration: The trial has been registered on US National Institutes of Health

ClinicalTrials.gov (NCT03704324).

Keywords: delirium, intensive care unit, surgical patients, critical care, postoperative care, prediction

model, nursing, protocol

This article is protected by copyright. All rights reserved. 


\section{INTRODUCTION}

Delirium is an acute and fluctuating alteration of mental state characterized by a disturbance in

attention, consciousness and cognition (A. P. Association, 2013). Postoperative delirium (POD) is a common postoperative complication that can occur in patients of any age(Aldecoa et al., 2017). The reported incidence of POD varies within a broad range due to different targeted population and different risk factors exposure(Smulter, Lingehall, Gustafson, Olofsson, \& Engstrom, 2013). A meta-analysis including 26 studies reported an incidence of 4.0 to $53.3 \%$ in patients after orthopaedic surgery(Bruce, Ritchie, Blizard, Lai, \& Raven, 2007). Critically ill patients admitted to Intensive Care Units (ICU) postoperatively had much higher incidence rates of POD compared with non-surgical ICU patients. Delirium affects up to $80 \%$ of mechanically ventilated adult patients in ICU and costs 4 to 16 billion dollars annually in the USA alone(Landro, 2011; Moyer, 2011). Postoperative delirium is associated with several negative outcomes, including increased mechanically ventilated days, hospital length of stay (LOS) and cost (Bellelli et al., 2014; Edelstein et al., 2004; Krzych et al., 2014; Witlox et al., 2010). Moreover, each day with a delirium is independently associated with an increased hazard of death by $10 \%$ (Ely et al., 2004). Delirium brings also great burden to patients and their families as the follow-up cognitive decline can persist for months to years hindering patients to return to their

This article is protected by copyright. All rights reserved. 
previous quality of life and employment (Norman et al., 2016). Although few studies have focused on exploring relevant factors and developing strategies to prevent the occurrence of POD, the evidence gap remains and needs to be further explored.

\subsection{Background}

Given the high prevalence of POD among critically ill patients and its associated negative clinical outcomes, there is a growing body of research exploring related risk factors and predictors to prevent the occurrence of delirium at the early stage. Although the number of studies on delirium increased in the past decade, an evidence gap still exists in this area due to the heterogeneity of previous researches and their results. First, the incidence varies a broad range because the targeted population are different (Aldecoa et al., 2017). In China, up to now, no studies have investigated the incidence

and risk factors of POD in surgical ICUs. Although there have been several studies exploring the potential risk factors of POD in ICU, most of these studies provide inconclusive evidence. The Benzodiazepine use and blood transfusion administration are the only two identified factors with strong evidence (Devlin et al., 2018). Hence, further studies are needed to focus on the aetiology of POD to find out modifiable and non-modifiable factors to verify presumed factors (Pandharipande et al., 2017).

This article is protected by copyright. All rights reserved. 
Since there is lack of effective treatments for POD, prevention remains the best strategy. Studies

have proven that preventive measures could help reduce the incidence, duration and severity of

delirium (Inouye et al., 1999; Kalisvaart et al., 2005). However, if preventive measures including

pharmacological, psychological or multicomponent interventions apply to all postoperative patients in

ICU, they might be time and cost consuming and may also expose patients to unnecessary risk of

adverse effects. Predictive models that include delirium risk factors can guide clinical practice to early

prevention of high-risk patients.

We undertook a systematic review to identify validated prediction models for POD using

PubMed, Embase, Medline and CINAHL. Ten prediction instruments were identified, of which only

two were developed for ICU patients, named PRE-DELIRIC (van den Boogaard et al., 2012; van den

Boogaard et al., 2014) and E-PRE-DELIRIC (Wassenaar et al., 2015). The PRE-DELIRIC model is

designed to detect high-risk patients within 24 hours after ICU admission, while the E-PRE-DELIRIC

model can be used during ICU admission. However, both models were developed in general ICU

patients and not fully considering the impact of surgical patients. The other eight identified models

were for hip surgery (Kalisvaart et al., 2006; Moerman et al., 2012), cardiac surgery (Koster,

Oosterveld, Hensens, Wijma, \& van der Palen, 2008; Rudolph et al., 2009), vascular surgery (Bohner

This article is protected by copyright. All rights reserved. 
et al., 2003), non-cardiac surgery (Marcantonio et al., 1994) and general surgery (Dworkin, Lee, An,

\& Goodlin, 2016; Kim, Park, Kim, \& Cho, 2016). Most of these models were developed based on

preoperative data and did not target ICU patients.

Limited knowledge exists on the incidence, risk factors and outcomes of POD in the Asian

population. So far, there is no delirium prediction model only for surgical ICU patients who may have

high exposures to POD. In addition, limited studies have focused on long-term outcomes of delirious

patients. Therefore, our PostopeRativE Delirium in Intensive Care unit patient (PREDICt) study can

contribute to a deeper understanding of the incidence and risk factors of delirium in Chinese surgical

patients during and after an ICU admission. The results of the PREDICt study can provide an

evidence base for early identification of POD in surgical ICU patients that might improve clinical

practice and ultimately long-term patient outcomes.

\section{THE STUDY}

\subsection{Aims}

The aim of the PREDICt study is to identify risk factors of postoperative delirium in surgical ICU

patients and to develop a prediction model to assess the outcomes of delirious post-surgical patients. This article is protected by copyright. All rights reserved. 
The specific study objectives are:

1. to determine the incidence, severity and categories of POD in surgical ICU patients and investigate

the modifiable and non-modifiable risk factors for the occurrence;

2. to develop and validate a risk model to predict POD in surgical ICU patients to identify high-risk

patients.

3. to identify short- and long-term outcomes of POD patients and explore the predictors for long-term

prognosis of patients who had POD in surgical ICU.

\subsection{Study Design}

This is a single-centre, prospective cohort study conducted at a tertiary teaching hospital in Shanghai,

China. The trial has been registered at the US National Institutes of Health ClinicalTrials.gov

(NCT03704324).

\subsection{Setting}

The study will be conducted in three surgical ICUs in XX hospital, Shanghai, China, which is the

largest hospital in Shanghai with 2005 beds. In 2017, the hospital performed 98,146 surgical

operations and the mean hospital length of stay after surgery was 5.95 days. The three ICUs are: 1)

This article is protected by copyright. All rights reserved. 
Comprehensive surgical ICU with 28 beds and the ICU staff include 96 nurses and physicians.

Approximately 50 postoperative patients per week are admitted, including thoracic surgery, general

surgery, orthopaedic surgery, urological surgery and vascular surgery; 2) Cardiac surgical ICU with

39 beds and the ICU staff include 121 nurses and physicians This ICU admits around 100

postoperative patients per week; 3) Liver surgical ICU with 25 beds and the ICU staff include 56

nurses and physicians. This ICU admits around 80 postoperative patients per week.

\subsection{Participants}

\section{Inclusion Criteria}

Patients aged above 18 with a planned admission to the surgical ICU after a surgical procedure will be

eligible for inclusion.

\section{Exclusion Criteria}

Exclusion criteria include preoperative delirium, dementia, patients who are unable to fully participate

in delirium testing, including patients who are blind, deaf, illiterate or inability to understand Chinese.

This article is protected by copyright. All rights reserved. 
Patients transferred from the ward directly to the ICU, not via the operation room, will be excluded.

Surgical patients with an emergency or unplanned ICU admission are also excluded.

Patients will be recruited in two cohorts during two periods. The recruitment of the first cohort

(developing cohort) will be from November 2018 - March 2019. The second cohort (validating

cohort) will be recruited from June 2019 - December 2019. The study framework presented in Figure

1 described the recruitment of both cohorts, including the time frames and the data collection.

\subsection{Sample size}

The aim of the study is to characterize the incidence and profiles of POD in ICU. We calculated the

sample size based on the POD guidelines of the European Society of Anaesthesiology (Aldecoa et al.,

2017), the reported incidence varies from $3.6 \%$ to $53.3 \%$. We used the lowest incidence $3.3 \%$

(Andersson, Gustafson, \& Hallberg, 2001; Bruce et al., 2007) to estimate the sample size of 253 with

a precision of 5\% and confidence level of $95 \%$. However, our study will also aim to identify risk

factors of POD and develop prediction model. The rule of thumb in logistic modelling is that a

minimum of 10 events per predictor variable (EPV) should be achieved based on simulation studies

This article is protected by copyright. All rights reserved. 
(Vittinghoff \& McCulloch, 2007). Therefore, we will target to recruit a minimum of 1000 patients to

minimise the limitation of a small number of events of postoperative delirium.

\subsection{Data collection}

\section{Delirium Assessment}

The primary outcome will be the presence of POD in ICU which often occurs up to five days after surgery (Olin et al., 2005; Sharma et al., 2005). Each patient will be assessed for delirium on postoperative day 1 and continuing for five days or until discharge from ICU. The delirium-positive patients will receive continuing assessment until hospital discharge. When patients have sudden change in mental status or behaviours, more frequent screening will be conducted. Before delirium assessment, Richmond Agitation-Sedation Scale (RASS) (Sessler et al., 2002) will be used to initially estimate the mental state of patients. If patients' RASS scored -4 or -5 , which means they can't response to voice, patients will not be screened for delirium until they regain consciousness. We defined patients with a POD if they have at least one positive screening during ICU stay. Two assessors will use instruments to interview medical staff caring for the patients and review the

This article is protected by copyright. All rights reserved. 
patient's medical record of the past 24 hours. If the two assessors disagree with the results, a

consensus panel consisting of two ICU physicians and one psychiatrist will make the final decision.

The Confusion Assessment Method for ICU (CAM-ICU) (Ely et al., 2001; Inouye et al., 1999)

and the CAM-ICU-7 (Khan et al., 2017) will be used to detect delirium and delirium severity. The

CAM-ICU is a validated and reliable tool to screen delirium and it needs $2-5 \mathrm{~min}$ to be completed

(Andrews, Silva, Kaplan, \& Zimbro, 2015; van den Boogaard et al., 2009). The CAM-ICU-7 is a

validated tool to assess delirium severity. It was derived from the CAM-ICU and RASS assessment

with 4 items and a 7-point rating scale (Table 1), categorized as 0-2: no delirium, 3-5: mild to

moderate delirium and 6-7: severe delirium (Khan et al., 2017). Both CAM-ICU and CAM-ICU-7 are

easy to use and less burdensome for nurses to conduct (van Eijk et al., 2009).

Delirium can present as hyperactive, hypoactive and mixed forms based on the clinical

presentation focused on psychomotor behaviour (Lipowski, 1983; Robinson, Raeburn, Tran, Brenner,

\& Moss, 2011). Hyperactive delirium is agitated and combative and often accompanied by

hallucinations and delusions. Patients showing decreased alertness, motor activity and anhedonia raise

suspicion for development of hypoactive delirium. Mixed delirium shows features of both conditions

(Fong, Tulebaev, \& Inouye, 2009; Meagher, O'Hanlon, O'Mahony, Casey, \& Trzepacz, 2000).

This article is protected by copyright. All rights reserved. 
Delirium subtype will be defined by CAM-ICU and RASS scores (Table 2). The Chinese version of

the screening and assessment tools have been translated and published in the latest Chinese guideline

by Chinese Medical Association Critical Care Medicine (CMACCM) Branch (Branch, 2018).

Over 6 months, all patients after surgery and ICU admission will be screened for delirium. Each

unit will have designated research staff for the collection and entry of data for the study.

\section{Demographic characteristic}

The demographic variables and related information on potential risk factors identified by three

systematic review (Gosselt, Slooter, Boere, \& Zaal, 2015; Kassie, Nguyen, Kalisch Ellett, Pratt, \&

Roughead, 2017; Oh et al., 2015) and two guidelines (Aldecoa et al., 2017; Devlin et al., 2018) related

to POD will be used. We will also include other variables based on clinical experience. The list of

study variables and their timeframe are presented in Table 3 . The demographic data will be collected

at preoperative day 1 and postoperative day 1 to day 5 respectively.

The patient baseline data will be prospectively extracted from the medical records and entered

into a database.

This article is protected by copyright. All rights reserved. 


\section{Preoperative baseline status}

Patients who are awake before surgery and with a planned postoperative ICU admission will receive preoperative assessment by nurses. The health-related quality-of-life (HRQoL) , activities of daily living, anxiety and depression level, sleep quality before surgery, duration of fluid fasting, pain level and ASA class (American Society of Anaesthesiologists Classification) will be evaluated and recorded by nurses and anaesthetists. Ability of hearing and vision will be assessed during the interview with the patients. We will use the numeric rating scale (NRS) to assess pain level and the Modified Barthel Index to measure activities of daily living (Shah, Vanclay, \& Cooper, 1989). The Hospital Anxiety and Depression Scale (HADS) (Zigmond \& Snaith, 1983) will be used to evaluate anxiety and depression level before surgery. Sleep quality will be assessed as good, average and bad according to patients' self-report. Patients' preoperative comorbidities will be assessed using the Charlson Comorbidity Index (CCI) (Charlson et al., 1986). Preoperative medications and examinations in the hospital will be extracted from the medical records. For liver surgery patients, the preoperative hepatic encephalopathy will be diagnosed and recorded by doctors; for cardiac surgery patients, the preoperative New York Heart Association (NYHA) functional classification will be evaluated and recorded by doctors.

This article is protected by copyright. All rights reserved. 


\section{Intraoperative risk factors}

Intraoperative data will be collected from the information system used at the operation theatres,

including date of surgery, surgical procedure, procedure urgency, type of anaesthesia, drug use, blood transfusion, operation time and arterial blood gas analysis. Occurrence of hypotension and duration

will be recorded, which is defined as Mean Arterial Pressure $<60 \mathrm{mmHg}$. For cardiac surgery patients,

duration of cardiopulmonary bypass, duration of cerebral perfusion (if any), number of bridge vessels

(if it is Coronary Artery Bypass Grafting) and aortic cross clamp time will be collected.

\section{Postoperative risk factors}

Postoperative data will be collected from the medical information system and nursing documents, including APACHE II (Acute Physiology And Chronic Health Evaluation scoring system II) and/or

EuroScore II (European System for Cardiac Operative Risk Evaluation II), blood transfusion, drug

use, duration of intubation, sedation and pain level, reoperation, examinations, time and pattern of

family visit, duration of extracorporeal life support treatment (including continuous renal replacement

therapy, intra-aortic balloon pump and extracorporeal membrane oxygenation), comorbidities and

length of surgical ICU stay and hospital stay. Vital signs and arterial blood gas analysis at ICU

This article is protected by copyright. All rights reserved. 
admission will also be recorded. Critical care Pain Observation Tool (CPOT) will be used to assess

pain level for intubated patients, the NRS will be used for non-intubated patients.

\section{Short-term and long-term outcomes}

Short-term outcomes are defined as duration of ICU stay, duration of hospital stay, hospital mortality and medical expense. Patients who had POD during ICU stay will be followed at 1 month, 3 months, 6 months, 12 months, 18 months and 24 months after hospital discharge. Patients will be asked the health state after hospital discharge via telephone or WeChat ${ }^{\circledR}$ (a most commonly used communication software in China). The mortality is defined as all-cause death postoperatively. The readmission is defined as all-cause readmission to hospital after initial discharge. The reason of readmission will also be recorded.

At 6 months, 12 months and 24 months, delirious patients will be invited to the hospital to revive

mental assessment by Mini Mental State Examination (MMSE) (Folstein, Folstein, \& McHugh,

1975). The HRQoL will be evaluated using the 12-Item Short Form Health Survey (SF-12) (Ware,

Kosinski, \& Keller, 1996). The questionnaire consists of 12 questions categorised into eight domains

(physical function, role physical, bodily pain, general health, vitality, social function, role emotion

and mental health). This generic instrument is shown to be valid and reliable in the Chinese

This article is protected by copyright. All rights reserved. 
population (Lam, Lam, Fong, \& Huang, 2013). The SF-12 will be investigated online by sojump

(website, 2018). The baseline of HRQoL will be evaluated for all participants before surgery.

\subsection{Data management}

All the data will be entered and stored in the Research Electronic Data Capture (REDCap), which will be securely locked, and password protected. It is supported and maintained by the Evidence-based centre of Fudan University. Data management and analysis, including data audit, import and tracking

will be done by the biostatisticians in the centre. Each patient will be given a study identification

number; all paper files will be imported to the database once completed.

\subsection{Statistical analysis}

The incidence of POD will be described by the percentage - number of patients diagnosed with

delirium after surgery divided by the total number of patients recruited in the study. The POD profile

will be presented by delirium duration, delirium severity, delirium subtypes and associated outcomes.

Delirium duration and severity, delirium subtype, associated outcomes and perioperative data recoded

will be summarized using descriptive statistics including mean, SD, median range and frequency

tables.

This article is protected by copyright. All rights reserved. 
For developing the prediction model, we will use univariate logistic regression to assess the

association between each potential determinant and the two groups (presence or absence of delirium).

We will include determinants which are statistically or clinically significant and exclude a prevalence rate below $10 \%$. Then we will use bootstrap resampling to model the prediction of POD given the included determinants using a multivariate logistic regression analysis (Moons et al., 2015; Steyerberg et al., 2001). We will use bootstrapping techniques to adjust for overfitting — that is, for overly optimistic estimates of the regression coefficients of the risk factors in the final model. Missing data will be handled using a multiple imputation procedure among the potential determinants. We will estimate the prediction ability of the model to discriminate between patients with and without delirium by using the area under the receiver operating characteristics curve (AUROC). The prediction model will be applied to the validation sample for the external validation. We will estimate the model performance by building a new AUROC.

The impact of delirium on short-term outcomes will be compared between patients' presence and absence of delirium. Delirium duration and severity will be divided into groups and associated outcomes will be compared between groups. Continuous variables will be compared using the Student's t-test or the Wilcoxon rank-sum; categorical variables will be compared by Pearson's $\mathrm{X}^{2}$ test This article is protected by copyright. All rights reserved. 
or Fisher's exact test. The long-term outcomes including mortality, readmission and HRQoL will be

compared among POD patients. Univariate and multi logistic regression will be used to find out

predictors of associated outcomes.

\subsection{Ethical considerations}

This study was approved by the Hospital Ethics Board in May 2018 (B2018-071). The study will be conducted in accordance with the International Council for Harmonization and Good Clinical Practice principles. The study will adhere to the ethical principles stated in the Declaration of Helsinki (W. M.

Association, 2018).

All patients will receive written and verbal information of the study before surgery. Written informed consent will be obtained before surgery. Patient have the right to withdraw from the study at any time. Data collection will be stopped, and patients' record will be deleted from the database if a

patient withdraws from the study.

\subsection{Validity, reliability and rigour}

In this study, we will use several instruments including CAM-ICU, CAM-ICU-7 and SF-12. The validity and reliability will be tested with the baseline data. The consistency test of CAM-ICU

between different auditors will be tested before the study. Furthermore, we will report the results of This article is protected by copyright. All rights reserved. 
the cohort study following the STROBE statement (von Elm et al., 2014) and report the prediction

model according to TRIPOD statement (Collins, Reitsma, Altman, \& Moons, 2015).

\section{DISCUSSION}

POD can cause a burden to patients both short-term and long-term. Although patients will be

recovered from their surgeries, families of patients with POD can experience difficulties with their

beloved once by the mental symptoms of delirium. As a consequence of both the complex ICU

environment and isolation from families in the ICU, patients who underwent major surgeries tend to

have higher possibilities to present delirium during ICU stay (Pipanmekaporn et al., 2015). To our

knowledge, no studies have been performed to develop a prediction model of delirium for surgical

ICU patients. The PREDICt study expects to develop a delirium prediction model for surgical ICU

patients based on comprehensive investigation of potential predictors. In clinical practice, the

prediction model resulting from our study might offer an effective tool for ICU nurses to detect

high-risk patients, which can inform nurses to implement preventive interventions at the early stage

and pay more attention to targeted patients. We expect that this tool can contribute to the reduction of

the incidence of POD in ICU and improve quality of life after ICU discharge.

This article is protected by copyright. All rights reserved. 
Our study will reveal the associated outcomes, especially the long-term outcomes of patients

with delirium in the ICU period. To better understand the impact of delirium on long-term outcomes,

we will determine the associated values and predictors of mortality, readmission and HRQoL. Our

findings will provide an understanding of different types and severity of delirium on the outcomes of

different kinds of patient populations. These findings will be useful for further intervention studies to

improve long-term outcomes of delirious patients.

\subsection{Limitations}

The study has several limitations. First, although we plan to recruit a large sample in our study, it's a

single centre which may lower the representativeness of the results. Patients recruited in this study are

from a large tertiary hospital, patients tend to have more serious disease and undergo more

complicated surgeries than patients in general hospitals. Second, we are using CAM-ICU and

CAM-ICU-7 to detect delirium and assess its severity twice a day, both instruments have high

sensitivity and specificity. However, as delirium status changes over time, it's difficult to exactly

depict the profile of delirium progression. Third, we acknowledge that the study only includes

surgical patients with a planned ICU admission. Surgical patients with an unplanned or urgent

postoperative ICU admission are excluded and can be at risk of POD (Wassenaar et al., 2015). We

This article is protected by copyright. All rights reserved. 
aim to study this specific group of patients in a follow-up study (Pandharipande et al., 2017). Lastly,

the prediction model developed in the PREDICt study will not be externally validated among a large

sample from another population, which will be conducted in a follow-up study.

\section{CONCLUSION}

POD is a frequent complication in patients admitted to an ICU postoperatively, which is associated

with morbidity and can be a burden to patients and their families. This study will offer a prediction

tool to recognize high-risk patients in ICU which can provide a reference for ICU nurses to implement

prevention strategies. Furthermore, the study will identify short-term and long-term outcomes of

delirium patients and explore predictors of long-term outcomes.

This article is protected by copyright. All rights reserved. 


\section{REFERENCES:}

Aldecoa, C., Bettelli, G., Bilotta, F., Sanders, R. D., Audisio, R., Borozdina, A., . . Spies, C. D.

(2017). European Society of Anaesthesiology evidence-based and consensus-based guideline on postoperative delirium. Eur J Anaesthesiol, 34(4), 192-214.

doi:10.1097/eja.0000000000000594

Andersson, E. M., Gustafson, L., \& Hallberg, I. R. (2001). Acute confusional state in elderly orthopaedic patients: factors of importance for detection in nursing care. Int J Geriatr Psychiatry, 16(1), 7-17. doi: 10.1002/1099-1166(200101)16:1<7::aid-gps261>3.0.co;2-w

Andrews, L., Silva, S. G., Kaplan, S., \& Zimbro, K. (2015). Delirium monitoring and patient outcomes in a general intensive care unit. Am J Crit Care, 24(1), 48-56.

doi:10.4037/ajcc2015740

American Psychiatric Association. (2013). Diagnostic and statistical manual of mental disorders

(DSM-5), 5th ed. Amer Psychiatric Pub Inc.

World Medical Association. (2018). Declaration of Helsinki - Ethical principles for medical research involving human subjects. Retrieved from

This article is protected by copyright. All rights reserved. 
https://www.wma.net/policies-post/wma-declaration-of-helsinki-ethical-principles-for-medica

1-research-involving-human-subjects/

Bellelli, G., Mazzola, P., Morandi, A., Bruni, A., Carnevali, L., Corsi, M.,. Annoni, G. (2014).

Duration of postoperative delirium is an independent predictor of 6-month mortality in older adults after hip fracture. J Am Geriatr Soc, 62(7), 1335-1340. doi:10.1111/jgs.12885

Bohner, H., Hummel, T. C., Habel, U., Miller, C., Reinbott, S., Yang, Q.,. Schneider, F. (2003).

Predicting delirium after vascular surgery: a model based on pre- and intraoperative data. Ann Surg, 238(1), 149-156.

Chinese Medical Association Critical Care Medicine Branch. (2018). Chinese guideline on analgesic and sedative treatment for adult patients in ICU Chin J Crit Care Intensive Care Med, 4(2), 90-113. doi: 10.3877/cma.j.issn.2096-1537.2018.02.002

Bruce, A. J., Ritchie, C. W., Blizard, R., Lai, R., \& Raven, P. (2007). The incidence of delirium associated with orthopedic surgery: a meta-analytic review. Int Psychogeriatr, 19(2), 197-214. doi:10.1017/s104161020600425x

This article is protected by copyright. All rights reserved. 
Charlson, M. E., Sax, F. L., MacKenzie, C. R., Fields, S. D., Braham, R. L., \& Douglas, R. G., Jr. (1986). Assessing illness severity: does clinical judgment work? J Chronic Dis, 39(6), 439-452. doi: 10.1016/0021-9681(86)90111-6

Collins, G. S., Reitsma, J. B., Altman, D. G., \& Moons, K. G. (2015). Transparent Reporting of a multivariable prediction model for Individual Prognosis or Diagnosis (TRIPOD): the TRIPOD statement. Ann Intern Med, 162(1), 55-63. doi:10.7326/m14-0697

Devlin, J. W., Skrobik, Y., Gelinas, C., Needham, D. M., Slooter, A. J. C., Pandharipande, P. P., . Alhazzani, W. (2018). Clinical Practice Guidelines for the Prevention and Management of Pain, Agitation/Sedation, Delirium, Immobility and Sleep Disruption in Adult Patients in the ICU. Crit Care Med, 46(9), e825-e873. doi:10.1097/ccm.0000000000003299

Dworkin, A., Lee, D. S., An, A. R., \& Goodlin, S. J. (2016). A Simple Tool to Predict Development of Delirium After Elective Surgery. J Am Geriatr Soc, 64(11), e149-e153. doi:10.1111/jgs.14428

Edelstein, D. M., Aharonoff, G. B., Karp, A., Capla, E. L., Zuckerman, J. D., \& Koval, K. J. (2004). Effect of postoperative delirium on outcome after hip fracture. Clin Orthop Relat Res(422), 195-200.

This article is protected by copyright. All rights reserved. 
Ely, E. W., Margolin, R., Francis, J., May, L., Truman, B., Dittus, R., . Inouye, S. K. (2001).

Evaluation of delirium in critically ill patients: validation of the Confusion Assessment

Method for the Intensive Care Unit (CAM-ICU). Crit Care Med, 29(7), 1370-1379. doi:

$10.1097 / 00003246-200107000-00012$

Ely, E. W., Shintani, A., Truman, B., Speroff, T., Gordon, S. M., Harrell, F. E., Jr., . . Dittus, R. S. (2004). Delirium as a predictor of mortality in mechanically ventilated patients in the intensive care unit. JAMA, 291(14), 1753-1762. doi:10.1001/jama.291.14.1753

Folstein, M. F., Folstein, S. E., \& McHugh, P. R. (1975). "Mini-mental state". A practical method for grading the cognitive state of patients for the clinician. J Psychiatr Res, 12(3), 189-198. doi: $10.1016 / 0022-3956(75) 90026-6$

Fong, T. G., Tulebaev, S. R., \& Inouye, S. K. (2009). Delirium in elderly adults: diagnosis, prevention and treatment. Nat Rev Neurol, 5(4), 210-220. doi: 10.1038/nrneurol.2009.24

Gosselt, A. N., Slooter, A. J., Boere, P. R., \& Zaal, I. J. (2015). Risk factors for delirium after on-pump cardiac surgery: a systematic review. Crit Care, 19, 346. doi: $10.1186 / \mathrm{s} 13054-015-1060-0$

This article is protected by copyright. All rights reserved. 
Inouye, S. K., Bogardus, S. T., Jr., Charpentier, P. A., Leo-Summers, L., Acampora, D., Holford, T.

R., \& Cooney, L. M., Jr. (1999). A multicomponent intervention to prevent delirium in hospitalized older patients. N Engl J Med, 340(9), 669-676.

doi:10.1056/nejm199903043400901

Kalisvaart, K. J., de Jonghe, J. F., Bogaards, M. J., Vreeswijk, R., Egberts, T. C., Burger, B. J., . van Gool, W. A. (2005). Haloperidol prophylaxis for elderly hip-surgery patients at risk for delirium: a randomized placebo-controlled study. J Am Geriatr Soc, 53(10), 1658-1666.

doi:10.1111/j.1532-5415.2005.53503.x

Kalisvaart, K. J., Vreeswijk, R., de Jonghe, J. F., van der Ploeg, T., van Gool, W. A., \& Eikelenboom, P. (2006). Risk factors and prediction of postoperative delirium in elderly hip-surgery patients: implementation and validation of a medical risk factor model. J Am Geriatr Soc, 54(5), 817-822. doi:10.1111/j.1532-5415.2006.00704.x

Kassie, G. M., Nguyen, T. A., Kalisch Ellett, L. M., Pratt, N. L., \& Roughead, E. E. (2017). Preoperative medication use and postoperative delirium: a systematic review. BMC Geriatr, 17(1), 298. doi: 10.1186/s12877-017-0695-x

This article is protected by copyright. All rights reserved. 
Khan, B. A., Perkins, A. J., Gao, S., Hui, S. L., Campbell, N. L., Farber, M. O., . . B Boustani, M. A. (2017). The Confusion Assessment Method for the ICU-7 Delirium Severity Scale: A Novel Delirium Severity Instrument for Use in the ICU. Crit Care Med, 45(5), 851-857. doi:

\subsection{7/CCM.0000000000002368}

Kim, M. Y., Park, U. J., Kim, H. T., \& Cho, W. H. (2016). DELirium Prediction Based on Hospital Information (Delphi) in General Surgery Patients. Medicine (Baltimore), 95(12), e3072. doi: 10.1097/MD.0000000000003072

Koster, S., Oosterveld, F. G., Hensens, A. G., Wijma, A., \& van der Palen, J. (2008). Delirium after cardiac surgery and predictive validity of a risk checklist. Ann Thorac Surg, 86(6), 1883-1887. doi:10.1016/j.athoracsur.2008.08.020

Krzych, L. J., Wybraniec, M. T., Krupka-Matuszczyk, I., Skrzypek, M., Bolkowska, A., Wilczynski, M., \& Bochenek, A. A. (2014). Detailed insight into the impact of postoperative neuropsychiatric complications on mortality in a cohort of cardiac surgery subjects: a 23,000-patient-year analysis. J Cardiothorac Vasc Anesth, 28(3), 448-457. doi:10.1053/j.jvca.2013.05.005

This article is protected by copyright. All rights reserved. 
Lam, E. T., Lam, C. L., Fong, D. Y., \& Huang, W. W. (2013). Is the SF-12 version 2 Health Survey a valid and equivalent substitute for the SF-36 version 2 Health Survey for the Chinese? J Eval Clin Pract, 19(1), 200-208. doi:10.1111/j.1365-2753.2011.01800.x

Landro, L. (2011). Changing intensive care to improve life afterward-WSJ.com. . Available at: http://online.wsj.com/article/SB10001424052748704081604576144321242020948.html., Accessed November 2011.

Lipowski, Z. J. (1983). Transient cognitive disorders (delirium, acute confusional states) in the elderly. Am J Psychiatry, 140(11), 1426-1436. doi:10.1176/ajp.140.11.1426

Marcantonio, E. R., Goldman, L., Mangione, C. M., Ludwig, L. E., Muraca, B., Haslauer, C. M.,. et al. (1994). A clinical prediction rule for delirium after elective noncardiac surgery. JAMA, 271(2), 134-139. doi: 10.1001/jama.1994.03510260066030

Meagher, D. J., O'Hanlon, D., O'Mahony, E., Casey, P. R., \& Trzepacz, P. T. (2000). Relationship between symptoms and motoric subtype of delirium. J Neuropsychiatry Clin Neurosci, 12(1), 51-56. doi:10.1176/jnp.12.1.51

This article is protected by copyright. All rights reserved. 
Moerman, S., Tuinebreijer, W. E., de Boo, M., Pilot, P., Nelissen, R. G., \& Vochteloo, A. J. (2012).

Validation of the Risk Model for Delirium in hip fracture patients. Gen Hosp Psychiatry,

34(2), 153-159. doi:10.1016/j.genhosppsych.2011.11.011

Moons, K. G., Altman, D. G., Reitsma, J. B., Ioannidis, J. P., Macaskill, P., Steyerberg, E. W.,.

Collins, G. S. (2015). Transparent Reporting of a multivariable prediction model for

Individual Prognosis or Diagnosis (TRIPOD): explanation and elaboration. Ann Intern Med,

162(1), W1-73. doi:10.7326/m14-0698

Moyer, J. (2011). Hospitals fight a form of delirium that often strikes ICU patients-The Washington

Post. Available at:

http://www.washingtonpost.com/national/health/hospitals-fght-a-form-of-delirium-that-often-

strikes-icu-patients/2011/03/23/AF518nMD_story.html., Accessed Novem-ber 2011.

Norman, B. C., Jackson, J. C., Graves, J. A., Girard, T. D., Pandharipande, P. P., Brummel, N. E., .

Ely, E. W. (2016). Employment Outcomes After Critical Illness: An Analysis of the Bringing

to Light the Risk Factors and Incidence of Neuropsychological Dysfunction in ICU Survivors

Cohort. Crit Care Med, 44(11), 2003-2009. doi: 10.1097/CCM.0000000000001849

This article is protected by copyright. All rights reserved. 
Oh, E. S., Li, M., Fafowora, T. M., Inouye, S. K., Chen, C. H., Rosman, L. M., . . Puhan, M. A.

(2015). Preoperative risk factors for postoperative delirium following hip fracture repair: a systematic review. Int J Geriatr Psychiatry, 30(9), 900-910. doi: 10.1002/gps.4233

Olin, K., Eriksdotter-Jonhagen, M., Jansson, A., Herrington, M. K., Kristiansson, M., \& Permert, J. (2005). Postoperative delirium in elderly patients after major abdominal surgery. Br J Surg, 92(12), 1559-1564. doi:10.1002/bjs.5053

Pandharipande, P. P., Ely, E. W., Arora, R. C., Balas, M. C., Boustani, M. A., La Calle, G. H., .Smith, H. A. B. (2017). The intensive care delirium research agenda: a multinational, interprofessional perspective. Intensive Care Med, 43(9), 1329-1339. doi: $10.1007 / \mathrm{s} 00134-017-4860-7$

Pipanmekaporn, T., Chittawatanarat, K., Chaiwat, O., Thawitsri, T., Wacharasint, P., \& Kongsayreepong, S. (2015). Incidence and risk factors of delirium in multi-center Thai surgical intensive care units: a prospective cohort study. J Intensive Care, 3, 53. doi: $10.1186 / \mathrm{s} 40560-015-0118-\mathrm{z}$

This article is protected by copyright. All rights reserved. 
Robinson, T. N., Raeburn, C. D., Tran, Z. V., Brenner, L. A., \& Moss, M. (2011). Motor subtypes of postoperative delirium in older adults. Arch Surg, 146(3), 295-300. doi: 10.1001/archsurg.2011.14

Rudolph, J. L., Jones, R. N., Levkoff, S. E., Rockett, C., Inouye, S. K., Sellke, F. W., . . Marcantonio, E. R. (2009). Derivation and validation of a preoperative prediction rule for delirium after cardiac surgery. Circulation, 119(2), 229-236. doi: 10.1161/CIRCULATIONAHA.108.795260

Sessler, C. N., Gosnell, M. S., Grap, M. J., Brophy, G. M., O'Neal, P. V., Keane, K. A., . . Elswick, R. K. (2002). The Richmond Agitation-Sedation Scale: validity and reliability in adult intensive care unit patients. Am J Respir Crit Care Med, 166(10), 1338-1344.

doi:10.1164/rccm.2107138

Shah, S., Vanclay, F., \& Cooper, B. (1989). Improving the sensitivity of the Barthel Index for stroke rehabilitation. J Clin Epidemiol, 42(8), 703-709.

Sharma, P. T., Sieber, F. E., Zakriya, K. J., Pauldine, R. W., Gerold, K. B., Hang, J., \& Smith, T. H. (2005). Recovery room delirium predicts postoperative delirium after hip-fracture repair.

This article is protected by copyright. All rights reserved. 
Anesth Analg, 101(4), 1215-1220, table of contents.

doi:10.1213/01.ane.0000167383.44984.e5

Smulter, N., Lingehall, H. C., Gustafson, Y., Olofsson, B., \& Engstrom, K. G. (2013). Delirium after cardiac surgery: incidence and risk factors. Interact Cardiovasc Thorac Surg, 17(5), 790-796.

doi: $10.1093 /$ icvts/ivt323

Steyerberg, E. W., Harrell, F. E., Jr., Borsboom, G. J., Eijkemans, M. J., Vergouwe, Y., \& Habbema, J. D. (2001). Internal validation of predictive models: efficiency of some procedures for logistic regression analysis. J Clin Epidemiol, 54(8), 774-781. doi:

10.1016/s0895-4356(01)00341-9

van den Boogaard, M., Pickkers, P., Slooter, A. J., Kuiper, M. A., Spronk, P. E., van der Voort, P. H., ... Schoonhoven, L. (2012). Development and validation of PRE-DELIRIC (PREdiction of DELIRium in ICu patients) delirium prediction model for intensive care patients: observational multicentre study. BMJ, 344, e420. doi: 10.1136/bmj.e420

van den Boogaard, M., Pickkers, P., van der Hoeven, H., Roodbol, G., van Achterberg, T., \& Schoonhoven, L. (2009). Implementation of a delirium assessment tool in the ICU can influence haloperidol use. Crit Care, 13(4), R131. doi: 10.1186/cc7991

This article is protected by copyright. All rights reserved. 
van den Boogaard, M., Schoonhoven, L., Maseda, E., Plowright, C., Jones, C., Luetz, A., . . .

Pickkers, P. (2014). Recalibration of the delirium prediction model for ICU patients

(PRE-DELIRIC): a multinational observational study. Intensive Care Med, 40(3), 361-369.

doi:10.1007/s00134-013-3202-7

van Eijk, M. M., van Marum, R. J., Klijn, I. A., de Wit, N., Kesecioglu, J., \& Slooter, A. J. (2009).

Comparison of delirium assessment tools in a mixed intensive care unit. Crit Care Med,

37(6), 1881-1885. doi:10.1097/CCM.0b013e3181a00118

Vittinghoff, E., \& McCulloch, C. E. (2007). Relaxing the rule of ten events per variable in logistic and

Cox regression. Am J Epidemiol, 165(6), 710-718. doi:10.1093/aje/kwk052

von Elm, E., Altman, D. G., Egger, M., Pocock, S. J., Gotzsche, P. C., \& Vandenbroucke, J. P.

(2014). The Strengthening the Reporting of Observational Studies in Epidemiology

(STROBE) Statement: guidelines for reporting observational studies. Int J Surg, 12(12),

1495-1499. doi:10.1016/j.ijsu.2014.07.013

Ware, J., Jr., Kosinski, M., \& Keller, S. D. (1996). A 12-Item Short-Form Health Survey: construction of scales and preliminary tests of reliability and validity. Med Care, 34(3), 220-233. doi:

10.1097/00005650-199603000-00003

This article is protected by copyright. All rights reserved. 
Wassenaar, A., van den Boogaard, M., van Achterberg, T., Slooter, A. J., Kuiper, M. A.,

Hoogendoorn, M. E., . . Pickkers, P. (2015). Multinational development and validation of an early prediction model for delirium in ICU patients. Intensive Care Med, 41(6), 1048-1056.

doi: 10.1007/s00134-015-3777-2

Online investigation website. (2018). SF-12 to evaluate the HRQoL of delirious patients. Available at:

https://www.wjx.cn/jq/30946952.aspx.

Witlox, J., Eurelings, L. S., de Jonghe, J. F., Kalisvaart, K. J., Eikelenboom, P., \& van Gool, W. A.

(2010). Delirium in elderly patients and the risk of postdischarge mortality,

institutionalization and dementia: a meta-analysis. JAMA, 304(4), 443-451.

doi:10.1001/jama.2010.1013

Zigmond, A. S., \& Snaith, R. P. (1983). The hospital anxiety and depression scale. Acta Psychiatr

Scand, 67(6), 361-370.

This article is protected by copyright. All rights reserved. 
Table 1 The Confusion Assessment Method for the ICU-7 Delirium Severity Scale

Items

Grading

\section{Acute onset or fluctuation of mental status}

Is the patient different than his/her baseline mental status? or Has the patient had any fluctuation in mental status in the past $24 \mathrm{hr}$ as evidenced by fluctuation on a sedation/level of consciousness scale (i.e.,

RASS/Sedation-Agitation Scale), Glasgow Coma Scale, or previous

delirium assessment?

\section{Inattention}

Say to the patient, "I am going to read you a series of 10 letters. Whenever you hear the letter 'A,' indicate by squeezing my hand.” Read letters from the following letter list in a normal tone $3 \mathrm{~s}$ apart. "SAVEAHAART" (Errors are counted when patient fails to squeeze on the letter " $\mathrm{A}$ " and when the patient squeezes on any letter other than "A.")

\section{Altered level of consciousness}

Present if the actual RASS score is anything other than alert and calm (zero)

\section{Disorganized thinking}

Yes/no questions

1. Will a stone oat on water?

2. Are there fish in the sea?

3. Does one pound weigh more than two pounds?

4. Can you use a hammer to pound a nail?
0 for absent

1 for present

0 for absent (correct: $\geq 8$ )

1 for inattention (correct: 4-7)

2 for severe inattention (correct: 0-3)

0 for absent (RASS: 0)

1 for altered level (RASS: $>1,<1$ )

2 for severe altered level (RASS: $>1,<-1$ )

Errors are counted when the patient incorrectly answers a question.

This article is protected by copyright. All rights reserved. 
Command: Say to patient "Hold up this many fingers" (Hold two fingers in

front of patient). "Now do the same with the other hand" (Do not repeat

number of fingers)

An error is counted if patient is unable to complete the entire command.

$\mathrm{ICU}=$ Intensive Care Unit; RASS = Richmond Agitation-Sedation Scale;

Table 2 Classification and definition of delirium subtype

\begin{tabular}{lll}
\hline Delirium subtype & CAM-ICU & RASS \\
\hline Hyperactive & positive & $+1 \sim+4$ \\
Hypoactive & positive & $0 \sim-3$ \\
Mixed & positive & both \\
\hline
\end{tabular}

CAM-ICU $=$ Confusion Assessment Method for Intensive Care Unit;

RASS $=$ Richmond Agitation-Sedation Scale

This article is protected by copyright. All rights reserved. 


\begin{tabular}{|c|c|c|c|c|c|c|c|c|c|c|}
\hline 数据录入表单 & $\begin{array}{l}\text { Perioperative } \\
\text { 术前访视 } \\
\text { (1) }\end{array}$ & $\begin{array}{c}\text { Intraoperative } \\
\text { 术中情况 } \\
\text { (2) }\end{array}$ & $\begin{array}{c}\text { Postoperative } \\
\text { in ICU 术后 } \\
\text { ICU } \\
\text { (3) }\end{array}$ & $\begin{array}{l}\text { Postoperative } \\
\text { in ward 术后 } \\
\text { 病房 } \\
(4)\end{array}$ & $\begin{array}{c}\text { Postoperative } \\
1 \text { month 出院 } \\
1 \text { 个月 } \\
\text { (5) }\end{array}$ & $\begin{array}{c}\text { Postoperative } \\
3 \text { month 出院 } \\
3 \text { 个月 } \\
\text { (6) }\end{array}$ & $\begin{array}{c}\text { Postoperative } \\
6 \text { month 出院 } \\
6 \text { 个月 } \\
\text { (7) }\end{array}$ & $\begin{array}{l}\text { Postoperative } \\
12 \text { month 出 } \\
\text { 院12个月 } \\
\text { (8) }\end{array}$ & $\begin{array}{l}\text { Postoperative } \\
18 \text { month 出 } \\
\text { 院18个月 } \\
\text { (9) }\end{array}$ & $\begin{array}{l}\text { Postoperative } \\
24 \text { month 出 } \\
\text { 院24个月 } \\
\text { (10) }\end{array}$ \\
\hline $\begin{array}{l}\text { Demographic } \\
\text { characteristic } \\
\text { 一般人口学资料 }\end{array}$ & $\checkmark$ & & & & & & & & & \\
\hline $\begin{array}{l}\text { Baseline } \\
\text { Status 术前基 } \\
\text { 本情况 }\end{array}$ & $\checkmark$ & & & & & & & & & \\
\hline $\begin{array}{l}\text { Health } \\
\text { related } \\
\text { quality of life } \\
\text { 健康质量调查 }\end{array}$ & $\checkmark$ & & & & & & $\checkmark$ & $\checkmark$ & & $\checkmark$ \\
\hline Delirium 诟妄 & & & $\checkmark$ & $\checkmark$ & & & $\checkmark$ & $\checkmark$ & & $\checkmark$ \\
\hline $\begin{array}{l}\text { Lab Tests And } \\
\text { Examination } \\
\text { 实验室和影像学 } \\
\text { 检查 }\end{array}$ & $\checkmark$ & & $\checkmark$ & & & & & & & \\
\hline $\begin{array}{l}\text { Surgical } \\
\text { Factors 手术因 } \\
\text { 素 }\end{array}$ & & $\checkmark$ & & & & & & & & \\
\hline $\begin{array}{l}\text { Postoperative } \\
\text { Vital Signs Icu } \\
\text { Admission 入 } \\
\text { ICU生命体征 }\end{array}$ & & & $\checkmark$ & & & & & & & \\
\hline $\begin{array}{l}\text { Postoperative } \\
\text { blood gas } \\
\text { analysis } \lambda I C U \\
\text { 血气 }\end{array}$ & & & $\checkmark$ & & & & & & & \\
\hline $\begin{array}{l}\text { Condition } \\
\text { Severity 疾病 } \\
\text { 严重程度 }\end{array}$ & & & $\checkmark$ & & & & & & & \\
\hline $\begin{array}{l}\text { ICU Sleep } \\
\text { quality ICU睡 } \\
\text { 眠质量 }\end{array}$ & & & $\checkmark$ & & & & & & & \\
\hline $\begin{array}{l}\text { External } \\
\text { Support 体外 } \\
\text { 医疗支持 }\end{array}$ & & & $\checkmark$ & & & & & & & \\
\hline $\begin{array}{l}\text { Medical } \\
\text { Support 术后 } \\
\text { 医疗支持 }\end{array}$ & & & $\checkmark$ & & & & & & & \\
\hline $\begin{array}{l}\text { Blood Support } \\
\text { 输血支持 }\end{array}$ & & & $\checkmark$ & & & & & & & \\
\hline $\begin{array}{l}\text { Reoperation } \\
\text { Possibility 再 } \\
\text { 次手术可能性 }\end{array}$ & & & $\checkmark$ & & & & & & & \\
\hline $\begin{array}{l}\text { Perioperative } \\
\text { Complications } \\
\text { 围手术期并发症 }\end{array}$ & $\checkmark$ & & $\checkmark$ & & & & & & & \\
\hline $\begin{array}{l}\text { Medication } \\
\text { Use 药物使用情 } \\
\text { 况 }\end{array}$ & $\checkmark$ & $\checkmark$ & $\checkmark$ & & & & & & & \\
\hline $\begin{array}{l}\text { Mortality 死亡 } \\
\text { 情况 }\end{array}$ & & & $\checkmark$ & & $\checkmark$ & $\checkmark$ & $\checkmark$ & $\checkmark$ & $\checkmark$ & $\checkmark$ \\
\hline $\begin{array}{l}\text { Readmission } \\
\text { 再入院 }\end{array}$ & & & & & $\checkmark$ & $\checkmark$ & $\checkmark$ & $\checkmark$ & $\checkmark$ & $\checkmark$ \\
\hline $\begin{array}{l}\text { MMSE 精神状 } \\
\text { 态评估 }\end{array}$ & & & & & & & $\checkmark$ & $\checkmark$ & & $\checkmark$ \\
\hline $\begin{array}{l}\text { General } \\
\text { report 患者情 } \\
\text { 况报告 }\end{array}$ & & & $\checkmark$ & & & & & & & \\
\hline
\end{tabular}

Table 3 Flow chart depicting the patients' timeline during the study.

MMSE $=$ Mini-Mental State Examination; ICU = Intensive Care Unit

This article is protected by copyright. All rights reserved. 


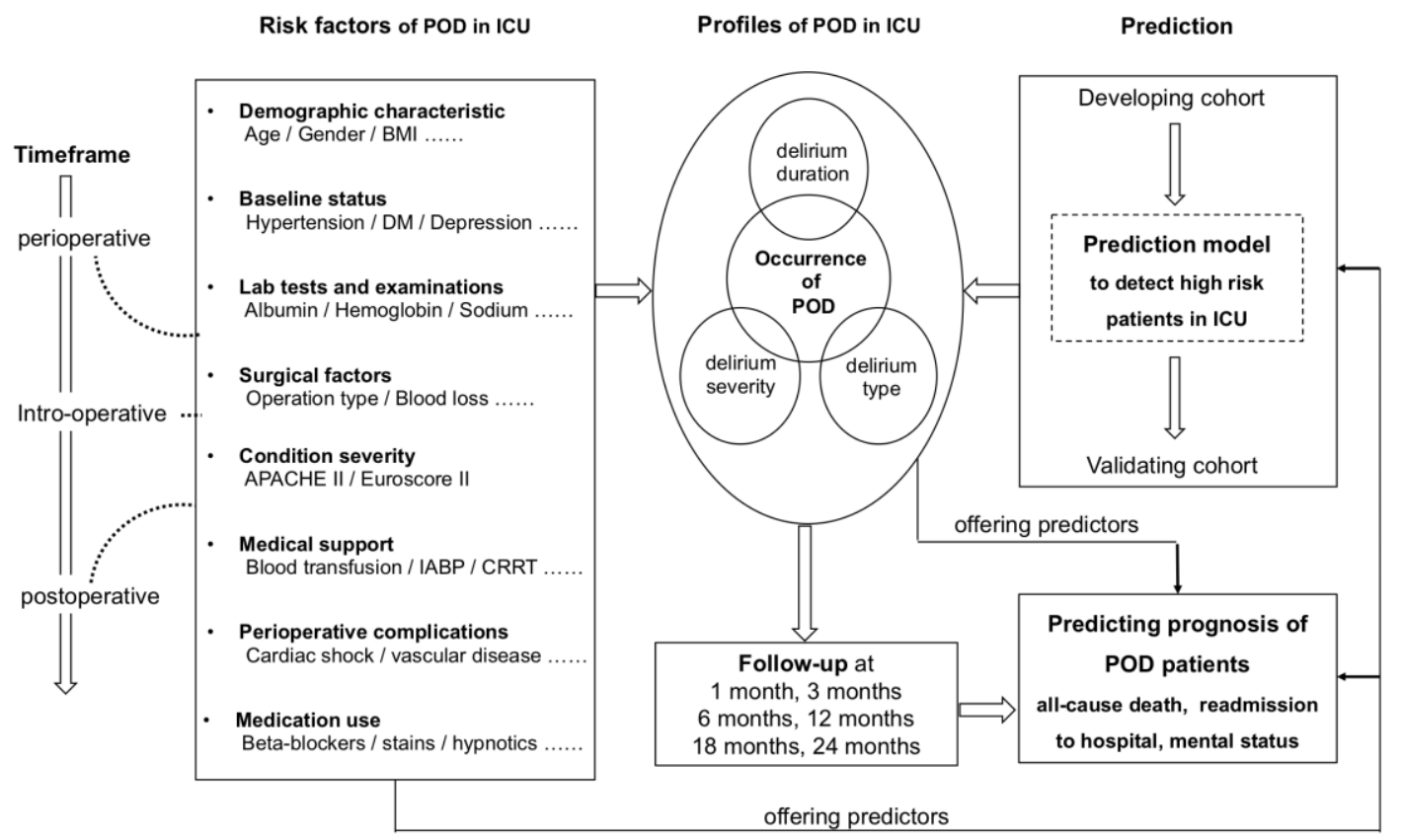

Figure 1 study framework

This article is protected by copyright. All rights reserved. 